Article

\title{
Residents' Preferences and Perceptions toward Green Open Spaces in an Urban Area
}

\author{
Liqin Zhang ${ }^{1,2}$, Huhua Cao ${ }^{1, *}$ and Ruibo Han $^{3}$ \\ 1 Department of Geography, Environment and Geomatics, University of Ottawa, Ottawa, ON K1N 6N5, \\ Canada; lzhan143@uottawa.ca \\ 2 Department of Public Administration, China University of GeoSciences (Wuhan), Wuhan 430074, China \\ 3 Center for Geospatial Information Science, University of Maryland, College Park, MD 20742, USA; \\ ruibo@umd.edu \\ * Correspondence: caohuhua@uottawa.ca; Tel.: +1-613-562-5800 (ext. 1043)
}

check for updates

Citation: Zhang, L.; Cao, H.; Han, R. Residents' Preferences and

Perceptions toward Green Open

Spaces in an Urban Area.

Sustainability 2021, 13, 1558.

https://doi.org/10.3390/su13031558

Received: 7 December 2020

Accepted: 25 January 2021

Published: 2 February 2021

Publisher's Note: MDPI stays neutral with regard to jurisdictional claims in published maps and institutional affiliations.

Copyright: (c) 2021 by the authors. Licensee MDPI, Basel, Switzerland. This article is an open access article distributed under the terms and conditions of the Creative Commons Attribution (CC BY) license (https:// creativecommons.org/licenses/by/ $4.0 /)$.

\begin{abstract}
Green open space is an important part of the natural-social ecosystem, providing ecological services that maintain the healthy development of cities and society. Residents' perceptions of these benefits are largely related to their social-economic background as well as their familiarity with the development of green open spaces in their neighborhoods. Understanding residents' perceptions of green open space will contribute significantly to urban planning by providing practical information that facilitates residents' needs. Using the urban development zone (UDZ) of Wuhan, this study aims to understand residents' preference toward green open space and their perceptions of ecological services and improvement, with the focus on the linking between social factors, preference, and views. In this study, data are collected through online questionnaire surveys and interviews. The results demonstrate how respondents' views vary and which social factors significantly relate to them. Significant changes in natural space changes are reflected in the public's perception of the ecological functions of these spaces. Responses to improving green open space reflect the residents pursuit of natural affinity and practicality. We conclude that it is better to enhance public involvement by providing residents' views, which helps to recognize actual needs in long-term green open space planning.
\end{abstract}

Keywords: public perception; green open space; preference; ecosystem services; China

\section{Introduction}

Throughout the past few decades, Chinese cities have dramatically evolved in terms of their physical landscapes and social economies [1]. Meanwhile, residents are becoming more aware of the negative ecological impacts of urban growth, such as increased urban pollution, health concerns, and reduced social-natural interactions. Green open spaces, including parks, gardens, greenbelt areas, wetland, etc., act as a place for socializing while also providing a variety of natural and social-ecological services, such as improved microclimates, purified air and improvement of the soil and water environment [2]. In this study, respondents' perceptions of these benefits are mostly influenced by their socialeconomic backgrounds and their familiarity with the development of green open space in their neighborhoods [3]. Understanding their views will contribute significantly to urban planning by providing practical information that facilitates residents' needs.

In an urban ecosystem, green open space is recognized as a crucial subsystem [4]. The attention toward green open space in cities of different income-level countries varies due to different socio-economic conditions. Equity, health, and safety benefits related to a high quality of life are more concerns of residents in cities of high-income countries [5,6], while the loss of natural resources and degradation of natural subsystems caused by urban expansion are more concerning to those in lower-income countries [7]. Most research in cities of middle- or low-income countries argues that the key cause of vegetation loss is 
urbanization, leading to a range of perceived environmental problems [8-10]. In China, a middle-high-income country, both the ecological impacts of urbanization on green open space and ecological services provided by such draw the attention of researchers [11]. Nonetheless, how the public perceives the impacts and the services, and how they understand engagement with relevant planning and management is still being studied [12].

This study looks at the urban development zone (UDZ) of Wuhan, a second-tier city in central China, which is used to investigate residents' perception of green open space. The green open spaces in this study mainly refer to city parks, street parks, and community parks, which contain water areas and gray open spaces or not. The main objective is to better understand residents' preferences toward green open space and their perceptions of ecological services and improvement, with the focus on the linking between different social factors and views. To achieve the objective, three questions are proposed: (1) What are the main features of residents' preference and perceptions of green open space and their links? (2) How do the social features of residents affect their preference and perceptions of green open spaces' ecological services and their improvement? (3) What can we learn for public participation in green open space planning and management?

\section{Literature Review}

Interactions between natural and social subsystems initiate the process of urban growth. The public's understanding of green open space emphasizes awareness of social and ecological functions of the natural landscape. Their enjoyment of these spaces is based on and a result of their understanding of the benefits they can provide [13]. Residents preferences are related to their social characteristics and their perception of the quality of green open spaces. The literature found that the use of open green space is related to attributes like gender, age, income, education level, race, and cultural group [14,15]. A study by Jim and Shan (2013) in Guangzhou, China, shows that improving health and promoting children's growth have received great attention [15]. Wendel et al. (2012) in Latin American countries found that there are gender differences in the use of green space and that the inequality of urban green space distribution is widespread [16]. From the perspective of gender and age, residents demonstrate significant differences in the use of open green spaces. The research grouped the park visitors based on their social characteristics or visiting preferences based on a social perspective. The distribution and accessibility of green spaces play an important role in residents' preferences. Studies on Chinese cities such as Shanghai [17], Beijing [18], and Wuhan [19] show that the accessibility of green parks is related to the economic level of residents. In other words, it is similar to the conclusion that the area and abundance of urban green space in high-income countries are significantly related to the income level of residents [20,21].

Natural subsystems provide tangible and intangible ecological services. A great amount of literature focuses on green open space benefits to residents' health and life quality [22,23]. Residents' views of the services implicate their concern with different facets of urban development. Generally, residents notice more practical benefits than ecological ones [24]. For instance, they believe that urban parks are an appropriate location for exercise or socialization and they recognize the safety when visiting green open space as well as the environmental quality for their enjoyment of the exposure [25].

Residents' preferences in visiting will affect their perception of the importance of open green spaces to natural and social-ecological well-being. The concerns of wellbeing between groups with different behavior preferences are different, reflecting on the perception of ecological and cultural services. The social services of the ecosystem can strengthen the connection between people and nature and between people. Lo and Jim's (2012) research on Hong Kong states that "green space is mainly appreciated for its practical microclimate and convenient facilities, not because of its environmental and social functions"; "residents demand richer natural elements and auxiliary facilities"; and "Effective public participation" [14]. 
Residents' perceptions of the quality of the green open space and the degree of completeness of facilities affect their visit purpose. In turn, the residents' visiting purposes affect their perceptions of green space defects and their improvement needs [26]. Generally speaking, the status and quality of the green open space will affect the behavior preferences of the visitors, and the behavior preferences of the visitors in turn affect their attention to the required configuration. Residents will pay attention to the natural and social services of the green open space while benefiting from the visit. Visit preference is associated with benefit perception. Residents who visit frequently are more concerned about the health promotion of green open spaces. At the same time, the green open space provides a place to promote social interaction, potentially promoting social interaction, although the service is different in the perception and preferences of different social groups. Additionally, from the perspective of the human living environment, personal growth and living environment will affect their perception, especially a good natural environment in childhood and adult perception of changes in the natural environment, both of which will have an impact on preferences and needs.

Though research stresses the public's attitude toward and perceptions of culturalecological services of green open space, it rarely detects the relationships between residents' preference and the influence on their perceptions of corresponding benefits provided by natural subsystems. Perceptions of benefits are affected not only by socioeconomic factors, like family status, economic class, or ethnic group $[27,28]$, but also by their experiences with nature. Scholars find that the experience of interacting with the natural environment in one's childhood affects his or her awareness of the natural landscape and preference for usage when he or she grows up [29]. Residents' experiences with the evolving environment also shape local awareness of land-use history which further affects their perceptions [30-32]. However, only a few studies incorporate these experiences into influencing factors, with focus on childhood experiences, not witnessing natural space changes.

Literature on public preferences toward greenness usually concentrates on specific urban parks [33], providing deductible findings that contribute to urban greenness planning and management. For example, Ayala-Azcárraga et al. (2019) compares nine parks in México City and finds that there is "a close relationship between patterns of visitor use and urban parks components such as distance, tree abundance, safeness, playground qualities and cleanliness" [34]. Studying urban green spaces without focusing on specific parks can provide more universal information for the planning and management of such spaces. The literature focuses on research on preferences and perceptions based on differences in social attributes, and it is a good attempt to incorporate preferences and changes in the living environment into influencing factors.

Knowledge of the use of green open spaces, such as exposure time and experience, is crucial to explain services provided by those spaces [35,36]. How the use of green open space relates to people's opinions on the improvement of the space attracts the interests of researchers in the fields of environment and health [37], community green space configuration [38], etc. Likewise, continuing to explore this topic is valuable for practical green open space provision in urban areas. Though literature focusing on perceptions of different services is popular, it is rare to compare or connect those facets, which will be done in this study.

This research introduces social characteristics, visiting preferences, experiences of environmental change, etc., to independent variables to analyze perceptions, attempting to establish the relationship between population, preference, and perception, as well as the relationship between preferences, services, and improvement. The study did not set a specific group of interviewees and communities and aimed to provide a basis for urban planning decision making on the social differences in the perception of residents in generalized urban spaces. 


\section{Study Area and Methods}

\subsection{Study Area}

Wuhan, the capital city of Hubei, is a large city located in central China. Being segregated by two natural belts, the Yangtze and Han rivers, Wuhan is historically a commercial center and transportation hub. This research focuses on the UDZ of Wuhan as defined in the latest city planning, where the severest physical and social transformations have been taking place. Wuhan urban land has grown quickly since 1990, with a 3.86-fold increase in the UDZ from $166.36 \mathrm{~km}^{2}$ in 1990 to $828.74 \mathrm{~km}^{2}$ in 2016. The population and GDP data are from the Wuhan Statistical Yearbook. The urban expansion data are derived from Landsat images. Wuhan has also experienced dramatic socio-economic growth, with its population increasing from 6.90 million in 1990 to 11.08 million in 2018. During that same period, its GDP increased from USD 2.71 billion to USD 227.37 billion (USD 1 = YUAN RMB 6.53, currency exchange rate on 29 December 2020). In the 1990s and early 2000s, significant transformations of green space and water area (wetland) to impervious surface occurred, accompanied by urban growth and population aggregation. Since the latter half of the 2000s, Wuhan has been paying more attention to the renewal, redevelopment, and conservation of its green and water space.

Figure 1 shows the Wuhan UDZ green system plan between 2010 and 2020, describing the structural and spatial characteristics of the various types of green spaces. Parks and urban vegetated areas, which are the focus of this survey, constitute the major parts of green open spaces in the urban area. Small-scale green spaces in the city center provide services to nearby communities while big parks accommodate larger spatial residents.

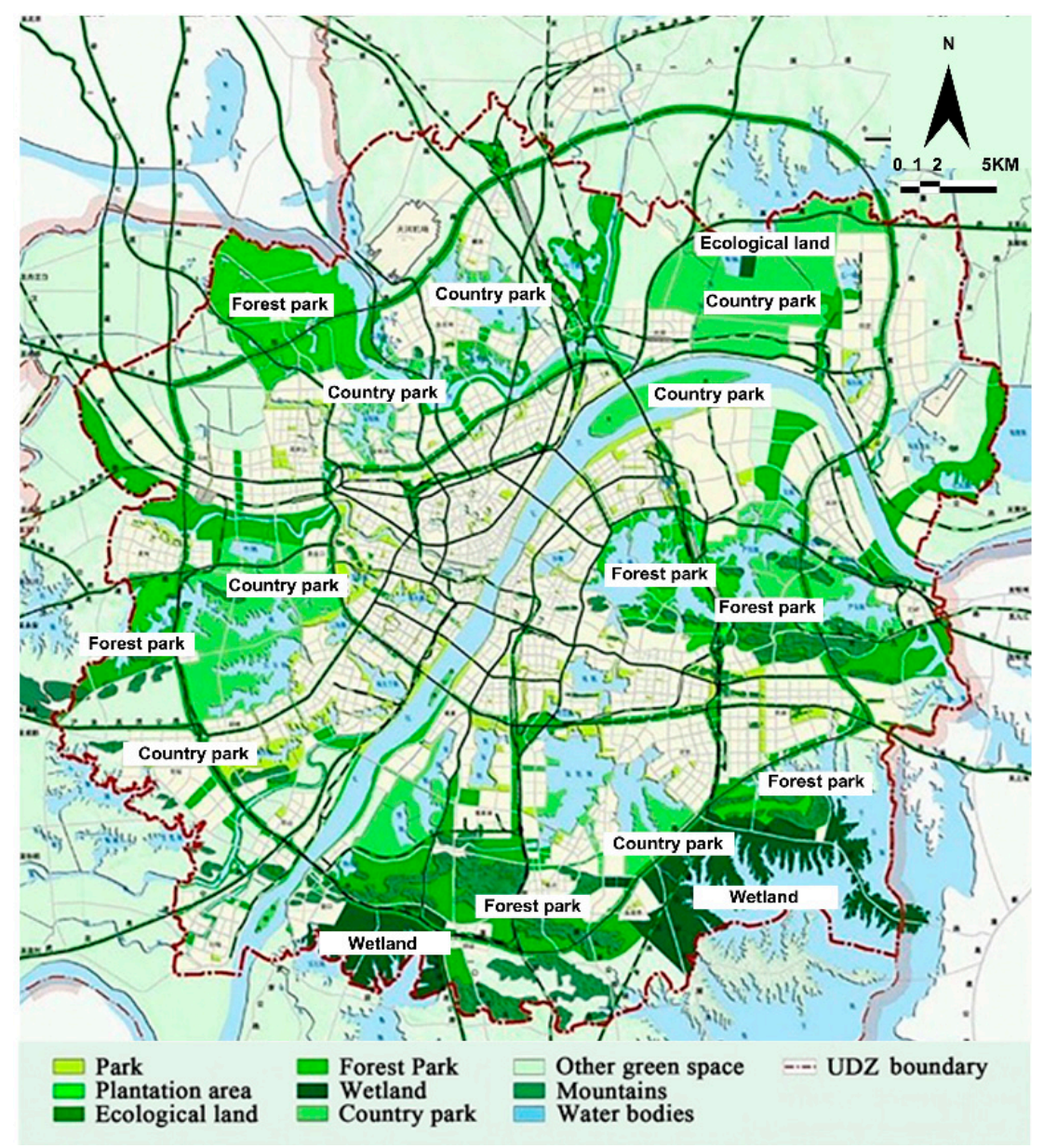

Figure 1. Map of study area. Edited based on urban development zone (UDZ) Green System Plan Map in the comprehensive Plan of Wuhan. http:/ /gtghj.wuhan.gov.cn/wu/pc-992-61109.html. 


\subsection{Data Collection and Analysis}

Questionnaire surveys are a popular approach to obtain data for semi-quantitative analysis, while interviewing is often chosen for qualitative studies. In most studies, either questionnaire surveys or interviews are selected for analysis, with few using both. Since closed-question surveys have limitations on the disclosure of information implicated behind the data, personal interviews can be used to extract complementary information [39]. The surveys for this study were designed based on the literature [11,23,40-43], with consideration of the characteristics of the case city. Data was collected to advance this study through an online survey and interview among the selected participants to represent the population of Wuhan. Further, a web questionnaire was created using Questionnaire Star. The questionnaire link was then delivered by snowballing through WeChat, a popular social media platform in China. The snowballing began with acquaintances, colleagues, students, family, neighbors, etc. Data were collected automatically as participants completed the questionnaire, and the results could be downloaded.

The questionnaire was split into four parts, with closed-ended questions. It consisted of questions regarding personal information, residents' preferences of using green open spaces, and their perceptions of ecological services provided by, and improvement necessity of, those spaces.

The questionnaire survey provided an overview of the perspectives towards the ecological roles of green open space. However, more information was needed to fully address our research questions. Thus, we interviewed selected respondents based on their social variety and willingness to participate. The interview was held using WeChat one-one audio or video chat mode, and the content of the interview was typed based on the consent of the participants.

When analyzing the questionnaire data, we used percentages to assess the structure of perceptions in each category. We further quantified the perceptions with a Likert 5scale coding. That is, "strongly disagree, somewhat disagree, neutral, somewhat agree, strongly agree" are coded as 1, 2, 3, 4, and 5, respectively. A "a nonparametric rank-based" Kruskal-Wallis test was then conducted to determine in which social groups perceptions were significantly different. This helped to decide if the differences "between two or more groups of an independent variable" were statistically significant [44]. We took demography, preference, and experience information of respondents as independent variables, including gender, age, occupation, length of residence, preference of visiting green open space, and experience of green space changes.

To briefly describe the detailed differences between different groups, we further calculated a mean score to rank the perceptions. In statistics, it is often believed that data collected at the ordinal level should not use measurements at the interval level [45]. Many statistical theorists believe that it is impossible to calculate the mean of the codes denoting individual categories of the Likert scale [46]. However, in Advances in Health Sciences Education, Norman (2010) affirms that means and other parametric statistics can be utilized for Likert scale data analysis without concern of "getting the wrong answer", based on the dissection of critical arguments and empirical literature dating back to the 1930s [47]. In a psychological study, Uher (2018) also claims that parametric methods are effective for quantitative analysis of rating scale data [48]. Many empirical studies show that the mean score is even robust for ranking of Likert-scale data [49]. They simplify the ranking provides more information despite the differences of the structures behind the mean score being wrapped with no disclosure. Thus, we adopted the mean score to further identify the differences of perceptions between social groups and only used the scores to rank. The mean score is equal to the sum of "the proportion of respondents at different degrees agreeing multiplied by the corresponding value code" meaning that a smaller mean score would reflect a greater disagreement from respondents. 


\subsection{Information of Respondents}

In total, 418 participants were recruited. Those who failed the attention check $(n=93)$ for their residence in Wuhan were dropped. A total of 325 participants constitutes our final sample, with $44.31 \%$ male and $55.69 \%$ female: $17.23 \%$ aged $18-25$ (young), $59.08 \%$ aged 25-54 (middle-aged), and $23.69 \%$ aged 55 and over (elderly) (Table 1). Of the young respondents, $76.80 \%$ are students, whereas among the elderly group, $29.90 \%$ are civil servants, $18.20 \%$ are factory workers, and $14.30 \%$ are intellectuals. Occupations in the middle-aged group are relatively even, compared to the young or senior groups.

Table 1. Personal characteristics of respondents.

\begin{tabular}{|c|c|c|c|c|c|}
\hline \multicolumn{2}{|c|}{ Personal Characteristics } & \multirow{2}{*}{$\begin{array}{c}\text { Percentage (\%) } \\
44.31\end{array}$} & \multicolumn{2}{|c|}{ Personal Characteristics } & \multirow{2}{*}{$\begin{array}{c}\text { Percentage (\%) } \\
10.15\end{array}$} \\
\hline \multirow{2}{*}{ Gender } & Male & & \multirow{6}{*}{ Occupation } & Factory worker & \\
\hline & Female & 55.69 & & Businessperson & 10.46 \\
\hline \multirow{3}{*}{ Age } & Age 18-24 & 17.23 & & Civil servant & 12.00 \\
\hline & Age $25-54$ & 59.08 & & Intellectual & 15.08 \\
\hline & Age 55 and over & 23.69 & & Student & 23.08 \\
\hline \multirow{3}{*}{ Education } & Middle school or less & 2.15 & & Other & 29.23 \\
\hline & High school & 10.15 & \multirow{4}{*}{ Residential length } & Less than 5 years & 25.85 \\
\hline & College or above & 87.69 & & $5-10$ years & 18.46 \\
\hline \multirow{2}{*}{ Hukou * } & Urban Hukou & 76.31 & & $10-20$ years & 9.54 \\
\hline & Rural Hukou & 23.69 & & 20 years and over & 46.15 \\
\hline
\end{tabular}

* Hukou refers to the household registration status in China. It implicates where the person was raised. Hukou is different from districts/areas. In urban areas, there are also rural Hukou residents who are living in urban villages. Hukou implicates respondents' experience with nature in childhood, that is, respondents with rural Hukou, to a great extent, have experience with more natural interaction rather than those with an urban one.

Respondents with different occupations and residential lengths have different age structures. The younger group has a higher proportion of students and has lived in Wuhan for a shorter period, while the elderly group has higher proportion of factory workers and has lived in Wuhan for longer periods (Figure 2).

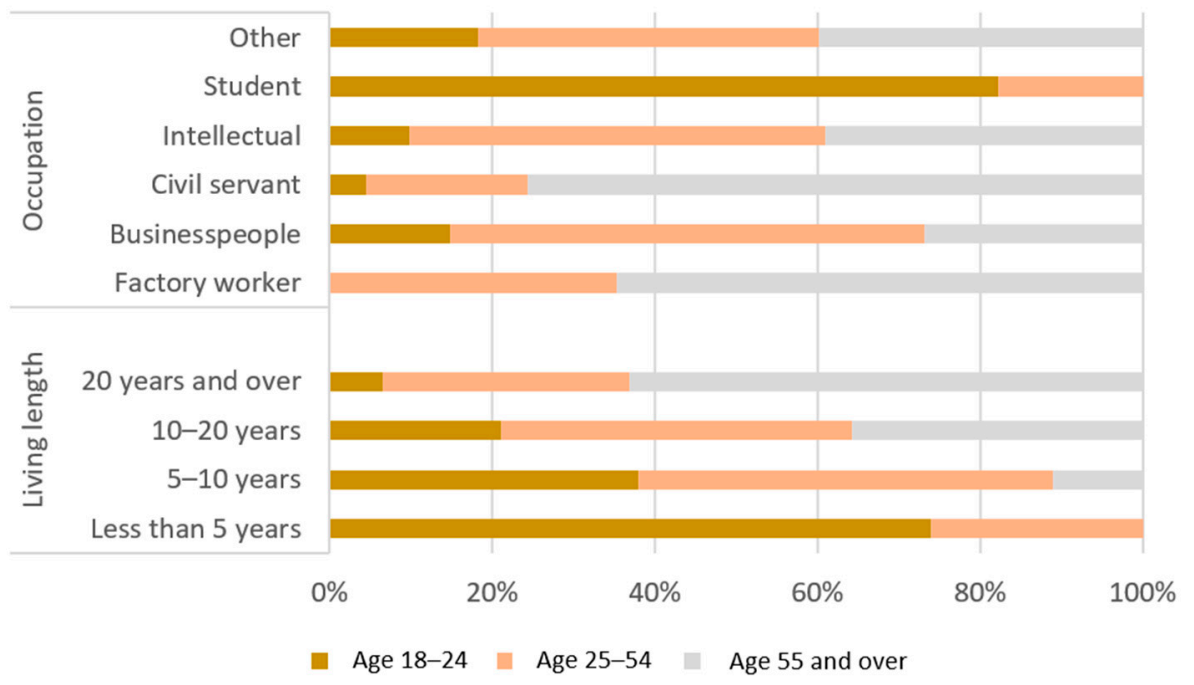

Figure 2. Age structure for respondents with different occupations and residential lengths.

\section{Preferences and Perceptions of Green Open Space}

Green open space provides many ecological services. The results demonstrate how selected participants use these spaces and link it to their perceptions toward the improvement 
of such areas. Moreover, how respondents perceive the benefits is also shown. The findings help to understand the relations between perceptions and their social characteristics, as well as links between various facets of such views.

\subsection{Benefits Provided by Green Open Space}

\subsubsection{Use of Green Open Space: Enjoying Benefits in Person}

Regarding the frequency of visits to green open space, $24.62 \%$ report that they visit daily; $28.31 \%$ visit weekly, $16.00 \%$ monthly, and $31.08 \%$ seldom visit. The structure in different ages, occupations, and residential length groups (Figure 3 ) shows that the elderly are likely to visit green spaces frequently, with $42.90 \%$ visiting daily. The young group has higher proportions (39.30\%) of weekly visits. Among occupation groups, civil servants report the most frequent visits.

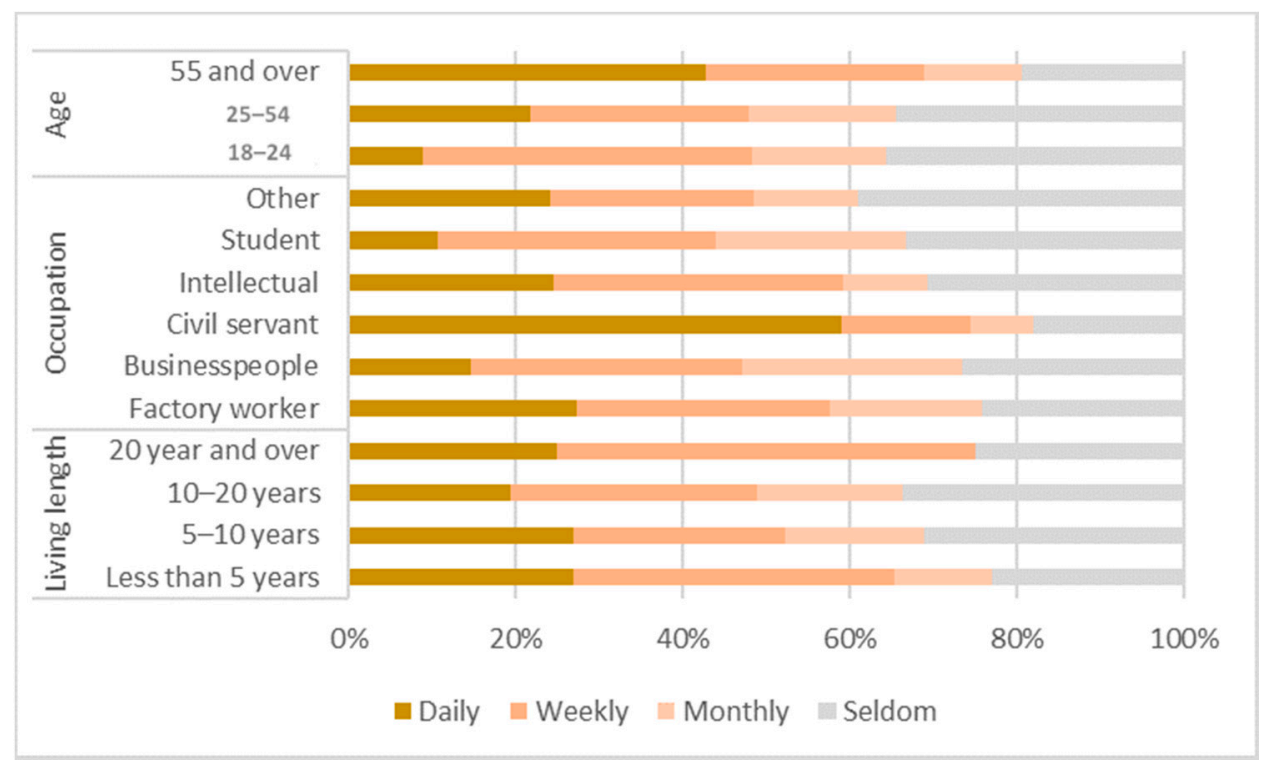

Figure 3. Frequency of visits by different social groups.

In terms of experiences with green space loss or gain in their neighborhoods, $12.00 \%$ of respondents report a great loss and $23.08 \%$ a slight one. Over a quarter $(26.46 \%)$ claim no changes have occurred. Of all respondents, $28.92 \%$ and $9.54 \%$, respectively, have seen a slight and great gain (Figure 4).

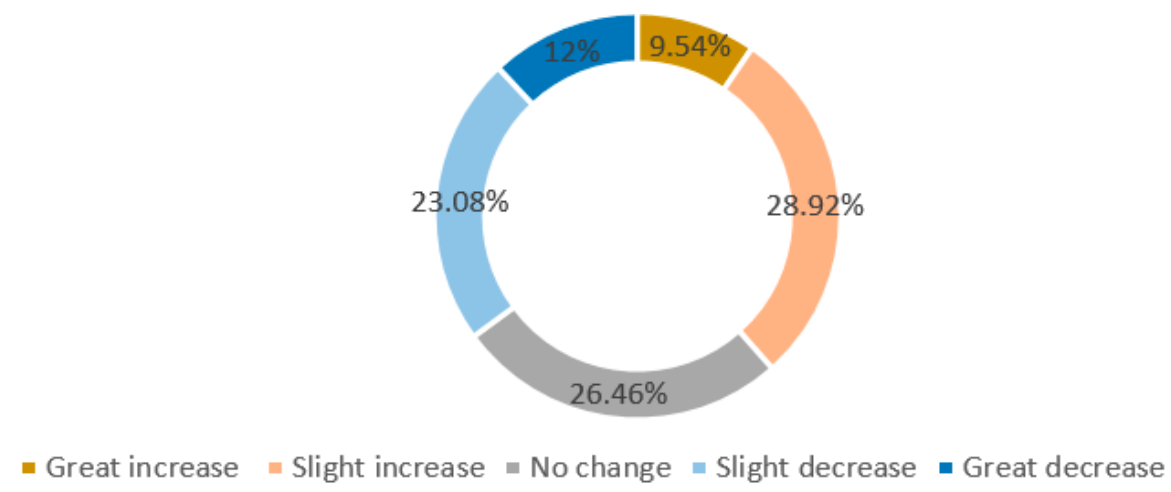

Figure 4. Perceived loss or gain of green space.

Respondents were asked their main reasons for visiting green open space. The question contains multiple choices, which means a respondent may visit with multiple motives. For example, one may visit green open spaces to walk, enjoy nature, and socialize at the same time. Thus, the intentions are overlapping and not mutually exclusive. The data were 
then coded into dichotomies based on each intention, in which "Yes (Y)" means to choose one option, such as to walk, "No (N)" means that option is not chosen. Overall, most respondents visit green open space to enjoy nature $(71.08 \%)$, walk $(64.62 \%)$, or exercise (43.08\%). Bicycling, social interactions, child's play, or other purposes are less common at $19.69 \%, 15.08 \%, 14.77 \%$, and $13.23 \%$, respectively (Figure 5).

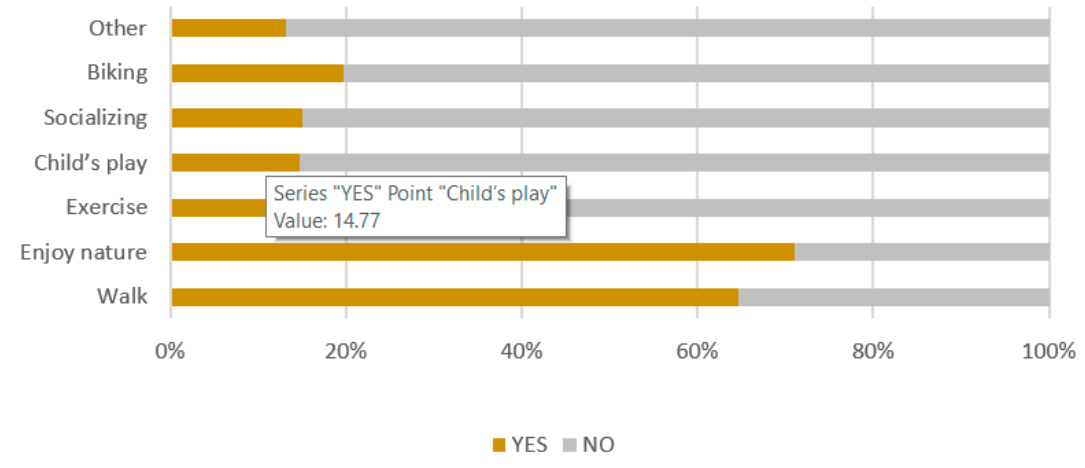

Figure 5. Green open space visit intention.

Social groups in the categories of age, Hukou, and occupation have significant differences in in-person enjoyment of green open space (Table 2), while gender and education have little influence. Younger and middle-aged participants tend to visit more to walk, enjoy nature, socialize, and ride their bicycles. Middle-aged respondents and elders mainly go for exercise and child's play. Urban Hukou participants enjoy visiting green open space to exercise, which links to individuals' health, whereas those with rural Hukou prefer going for walks, enjoying nature, socializing, and bicycle riding.

Table 2. $p$ Values of Kruskal-Wallis test: Social differences in intentions to visit.

\begin{tabular}{|c|c|c|c|c|c|c|c|c|c|c|c|c|c|c|}
\hline \multirow{2}{*}{ Intentions to Visit } & \multicolumn{2}{|c|}{ Walk } & \multicolumn{2}{|c|}{ Enjoy Nature } & \multicolumn{2}{|c|}{ Exercise } & \multicolumn{2}{|c|}{ Child's Play } & \multicolumn{2}{|c|}{ Socializing } & \multicolumn{2}{|c|}{ Biking } & \multicolumn{2}{|c|}{ Other } \\
\hline & $\mathbf{Y}$ & $\mathbf{N}$ & $\mathbf{Y}$ & $\mathbf{N}$ & $\mathbf{Y}$ & $\mathbf{N}$ & $\mathbf{Y}$ & $\mathbf{N}$ & $\mathbf{Y}$ & $\mathbf{N}$ & $\mathbf{Y}$ & $\mathbf{N}$ & $\mathbf{Y}$ & $\mathbf{N}$ \\
\hline Age & \multicolumn{2}{|c|}{$0.00^{* * *}$} & \multicolumn{2}{|c|}{$0.00^{* * *}$} & \multicolumn{2}{|c|}{0.29} & \multicolumn{2}{|c|}{$0.03 * *$} & \multicolumn{2}{|c|}{$0.02 * *$} & \multicolumn{2}{|c|}{$0.00^{* * *}$} & \multicolumn{2}{|c|}{0.86} \\
\hline Hukou & \multicolumn{2}{|c|}{$0.05 *$} & \multicolumn{2}{|c|}{$0.07^{*}$} & \multicolumn{2}{|c|}{$0.03^{* *}$} & \multicolumn{2}{|c|}{0.11} & \multicolumn{2}{|c|}{$0.02 * *$} & \multicolumn{2}{|c|}{0.11} & \multicolumn{2}{|c|}{0.49} \\
\hline Occupation & \multicolumn{2}{|c|}{$0.09 *$} & \multicolumn{2}{|c|}{0.39} & \multicolumn{2}{|c|}{0.20} & \multicolumn{2}{|c|}{$0.00^{* * *}$} & \multicolumn{2}{|c|}{$0.06 *$} & \multicolumn{2}{|c|}{0.37} & \multicolumn{2}{|c|}{0.30} \\
\hline Residential length & \multicolumn{2}{|c|}{0.08 * } & \multicolumn{2}{|c|}{$0.01^{* * *}$} & \multicolumn{2}{|c|}{0.35} & \multicolumn{2}{|c|}{$0.02 * *$} & \multicolumn{2}{|c|}{$0.01 * *$} & \multicolumn{2}{|c|}{0.29} & \multicolumn{2}{|c|}{0.10} \\
\hline
\end{tabular}

$p$ Value: ${ }^{* * *}, * *, *$ indicate the significance at the level of $0.01,0.05$, and 0.10 , respectively. "Y" means "Yes" for the choice of that visit purpose and "N" means "No" with no selection of that purpose.

Selected social differences of visit intention are shown in Figure 6. Civil servants have the greatest intentions to visit green open space for exercise while students have the lowest. Intellectuals have the highest interest in enjoying these spaces for child's play while students enjoy it for bicycle riding. This suggests that intellectuals consider the developmental benefits children may gain from green open space, compared to other occupational groups. Socializing in green open space is preferred the most by students, followed by businesspeople and intellectuals. The groups who rarely visit to socialize are factory workers, followed by civil servants. 


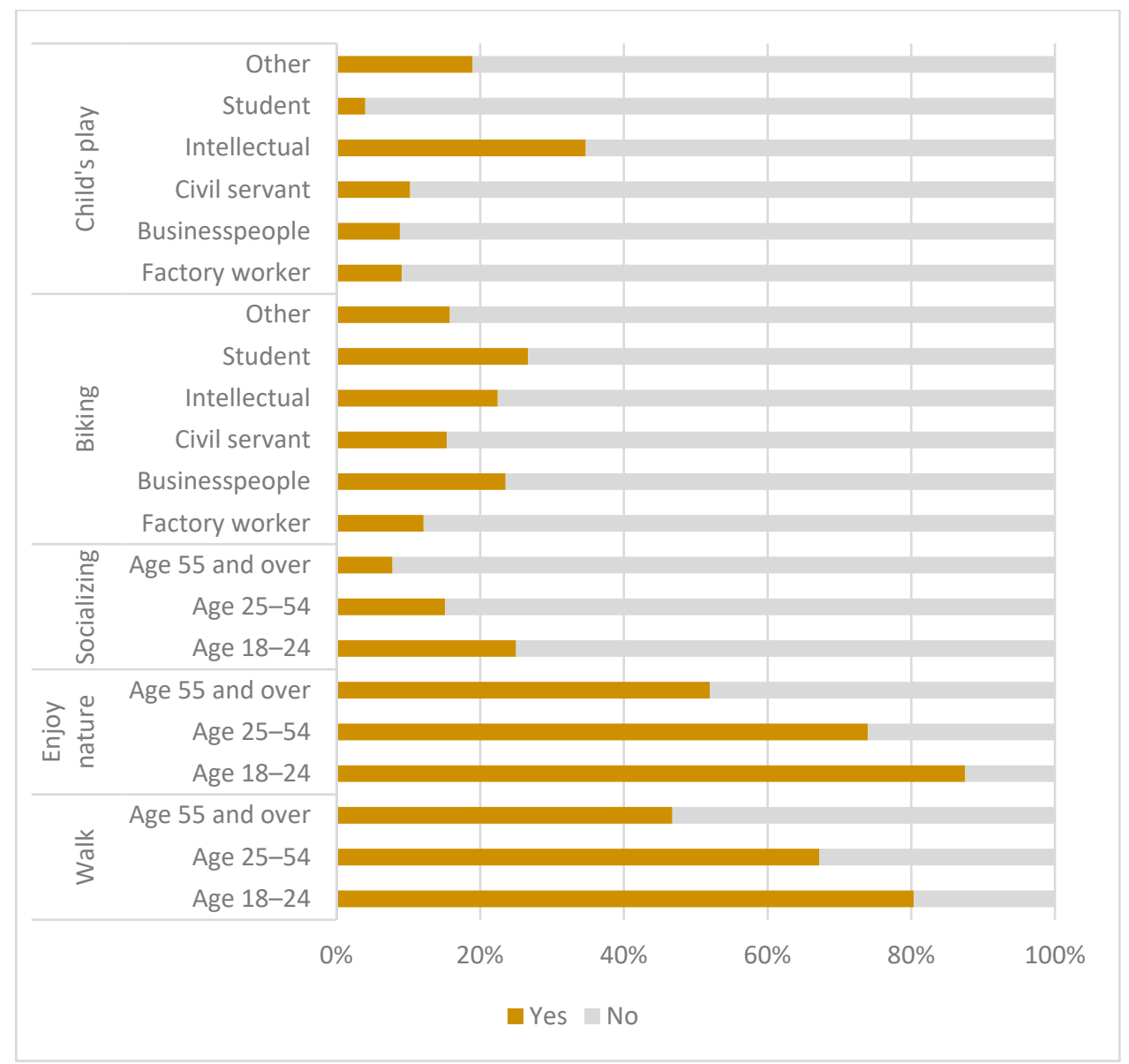

Figure 6. Purposes of visits by different occupational respondents.

\subsubsection{Perceptions of Benefits}

Respondents' awareness of ecological services is reflected by the importance of nature in their daily life [34]. Answers to the question "To what extent do you agree that green open spaces provide residents with the natural and social-ecological services?" show that the key concerns are air quality, noise reduction, and mitigation of urban heat island effects (Figure 7). When deciding if "green space and wetland significantly improve air quality", $87.69 \%$ of respondents agree and $1.23 \%$ disagree. Natural spaces are crucial habitats for biodiversity, while $4.92 \%$ of respondents disagree, showing less concern about habitats than for air quality improvement, noise reduction, and mitigation of urban heat island effects.

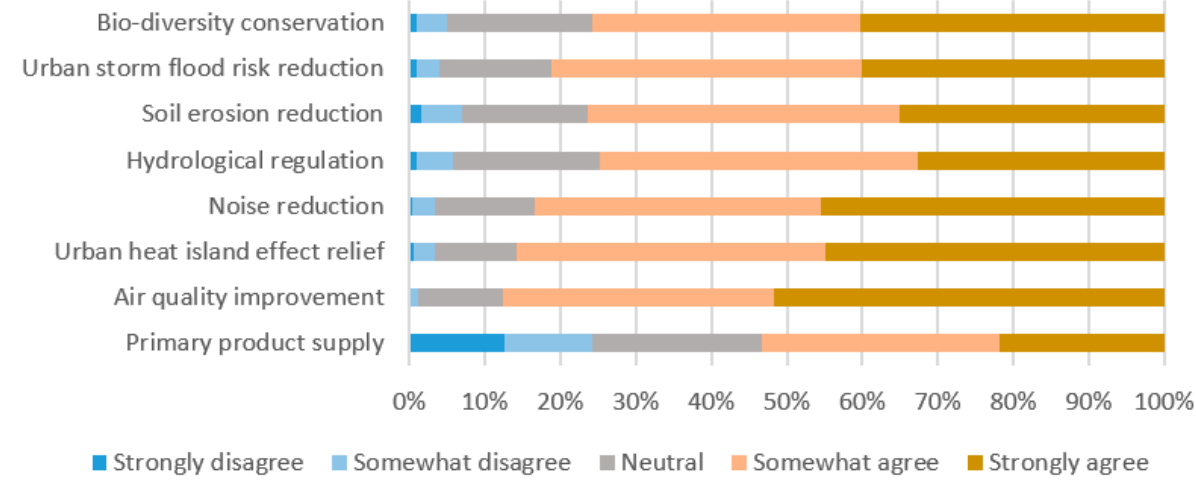

Figure 7. Perceptions of ecological services of green open spaces. 
Figure 8 provides the mean score of perception based on different social groups. In detail, gender affects perceptions of noise reduction by green open spaces, as fewer males (4.15) agree than females (4.33), which is the same when evaluating the services of storm flood reduction (male 4.05 and female 4.25). Hukou, which implies more experience with nature, influences how the benefits of urban heat island effect relief are perceived, with urban Hukou people (4.33) agreeing more than rural (4.06). Differences in age groups are only significant when they perceive primary product supply by green open spaces, for which elders agree (3.61) more and young people disagree (2.95) more. This is concurrent with differences by occupational categories as well as educational background. People with a higher educational background (3.31) tend to be more neutral than those with lower educational background (i.e., high school-educated population (4.14) and middle school-educated population (3.88)). Among occupation groups, those with the most neutral perceptions are students (2.93). Students also disagree with the services of noise reduction (4.00) and urban flood risk mitigation (3.89), compared to other occupations. A longer period of residency in Wuhan leads to a greater appreciation of the benefits of urban heat island mitigation and noise reduction by green open spaces. In-person visits to green open spaces affect residents' perception of services, such as primary product supply, air quality improvement, urban heat island relief, etc.

Experience of green space changes is reflected significantly in residents' perception of ecological services. Those who reported experiences of decreased green space tend to agree more strongly with natural space and a scattered distribution increase than those without, followed by those with experience of a great increase in green space.

From a social perspective, green open spaces benefit residents by promoting health and providing them with a place to relax. They also affect the value of residential properties. The benefits for physical and mental health are most important to residents, with $46.46 \%$ strongly agreeing and $42.15 \%$ somewhat agreeing (Figure 9). Only $1.54 \%$ participants opposed. It indicates that respondents recognize the vitality of green open space for their health in an urban context, with the least disagreement, no matter how frequently or for what purpose they visit the space. Of all respondents, $81.54 \%$ agree and $3.38 \%$ disagree that green open space acts as a place for daily leisure and recreation which benefits their daily lives. Much different from the three aspects above, green open spaces' effects on real estate value gained lower approval, with $22.77 \%$ of respondents disagreeing, suggesting that the other factors play more important roles.

Evaluating the social difference based on mean score (Figure 10) shows that in regard to gender, females (4.17) tend to agree more strongly with green open spaces' ability to promote community safety, while males (3.95) are more neutral or disagree. Age plays a significant role in the feeling about the daily use of green open space. Elders (4.27) and middle-aged respondents (4.25) tend to agree more strongly than younger respondents (3.89). Those with urban Hukou agree more than those with rural Hukou with socialecological services being a place for residents' daily leisure and recreation, conducive to physical and mental health, as well as for increasing real estate value. Discrimination is not significant when perceiving the community safety benefits provided by green open space. Educational background does not influence social-ecological services perceived, while occupation does. When evaluating the services of green open space for daily relaxation, students (3.83) tend to be more neutral or disagree, compared to the other occupations. Students thought similarly of other possible benefits like health, safety, and real estate value. When evaluating community safety benefits provided by green open space, those most neutral and in disagreement are students (3.73), followed by intellectuals (3.98) and civil servants (4.00), while factory workers (4.36) and businesspeople (4.21) are in greatest agreement. Students present the lowest mean score (3.11), followed by civil servants (3.31), when evaluating green open spaces' function to increase real estate value. Those who have lived in Wuhan for a long time more strongly agree with these social services than newer residents, with significant discrimination when evaluating services of daily relaxation and health provided by green open space. The frequency of visits has little influence on 
participants' perceptions of these services. People who visit green open spaces for child's play pay great attention to the improvement of related facilities in these spaces.

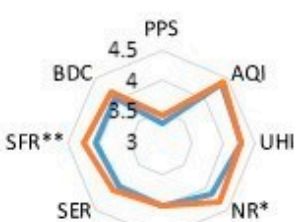

HR

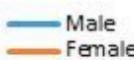

a. Gender

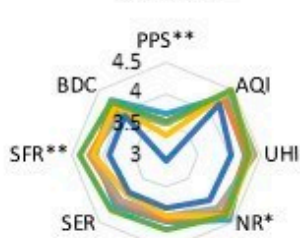

HR

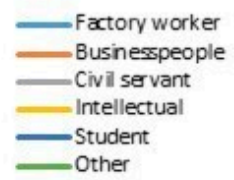

e. Occupation

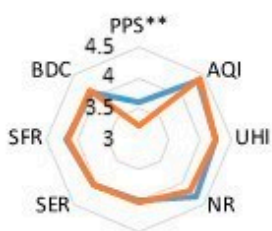

HR

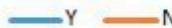

i. Visit for exercise

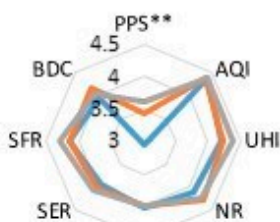

$H R$

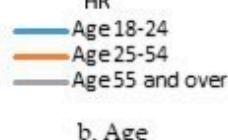

b. Age

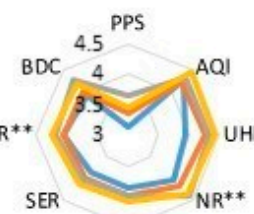

HR
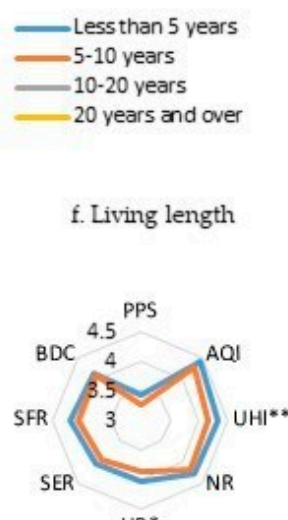

$H R^{*}$

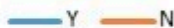

j. Visit for enjoying nature

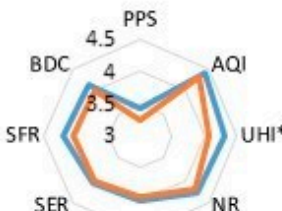

HR

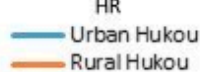

c. Hukou

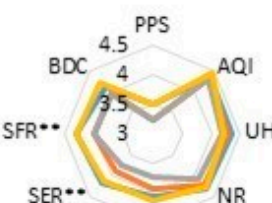

$H R$ *

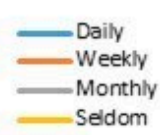

g. Visit frequency

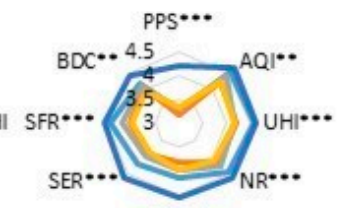

$H R *$.

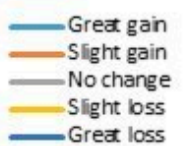

h. Green spaceloss/gain

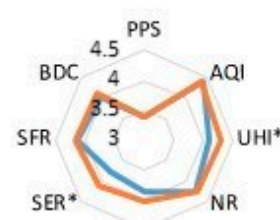

HR

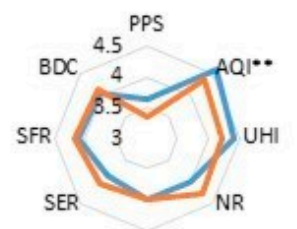

HR

PPS: primary product supply; AQI: air quality improvement; UHR: urban heat island relief; NR: noise reduction; HR: hydrological regulation; SER: soil erosion reduction; SFR: storm flood risk reduction; BDC: bio-diversity conservation

P value: $* *, *$ indicates the significance of Kruskal Wallis' test at the level of $0.01,0.05$, and 0.10 , respectively.

Figure 8. Social differences in perception of ecological services (based on mean scores).

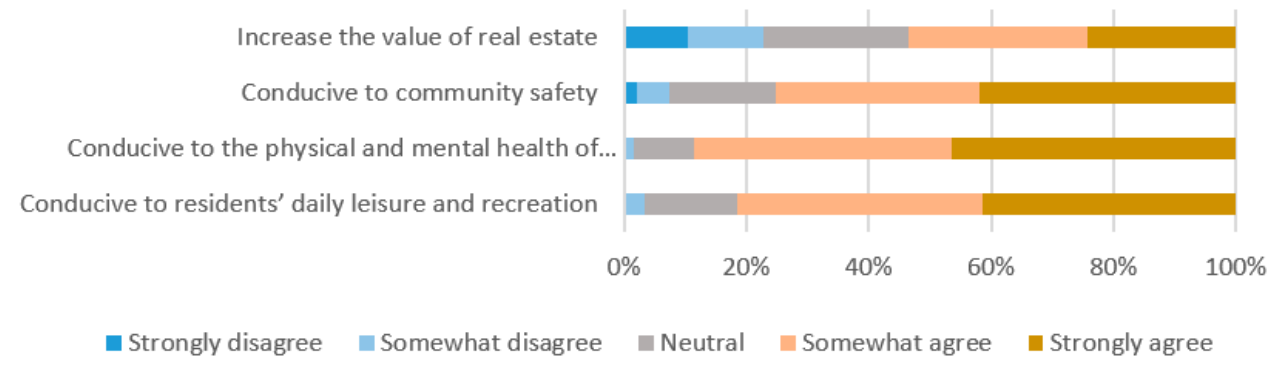

Figure 9. Perceptions of social services provided by green open space. 

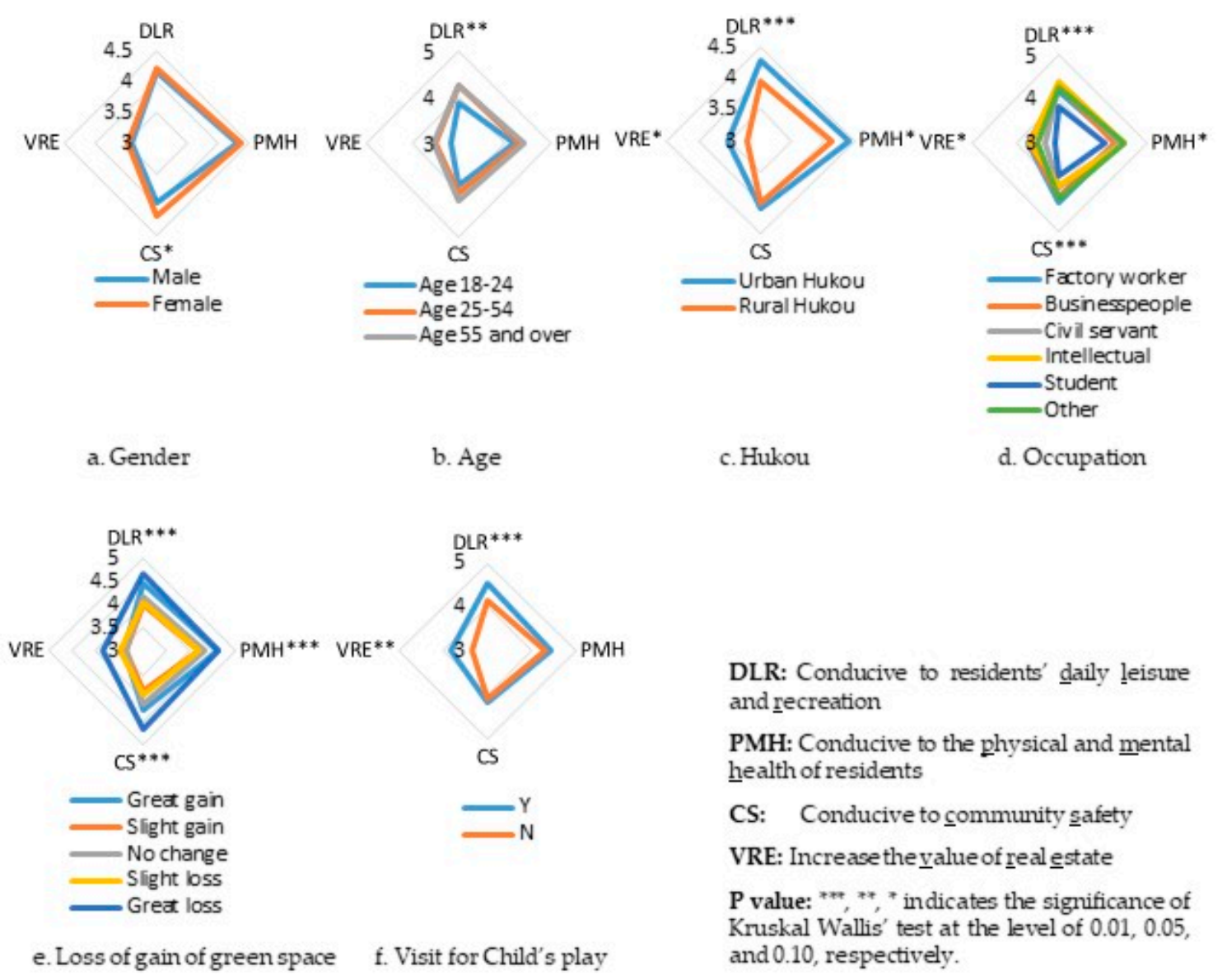

\begin{abstract}
DLR: Conducive to residents' daily leisure and recreation

PMH: Conducive to the physical and mental health of residents

CS: Conducive to community safety

VRE: Increase the value of real estate

P value: ${ }^{* *}, * *,{ }^{*}$ indicates the significance of Kruskal Wallis' test at the level of $0.01,0.05$, and 0.10 , respectively.
\end{abstract}

Figure 10. Differences in social service perception (based on mean scores).

Experience of green space changes significantly affects participants' perceptions of services for daily relaxation, promotion of health, and community safety. Those who experienced great changes, both decreases and increases, demand more for the socialecological services.

\title{
4.2. Disadvantages of Green Open Space
}

A person's view towards green open space quality depends on their intentions when visiting the area. People are more interested in benefiting from specific elements that meet their requirements. For example, those who visit to walk or enjoy nature will be more likely to recognize if it lacks green space. Those who mostly go to walk can also distinguish when walking trails are limited, whereas those who go for bicycle rides notice bicycle trails. It also suggests that respondents are more likely to perceive the shortage of exercise facilities, regardless of the reason for which they visit the green open space.

\subsubsection{Perceptions toward Natural Space Improvement}

The question for perception toward green open space improvement is "To what extent do you agree that improvement of natural elements and auxiliary facilities are essential in your neighborhood?"

In terms of natural space improvements, participants are concerned most with the quality of water bodies, followed by the development of wetlands and green areas (Figure 11). Of all respondents, $75.08 \%$ agree that developing additional green space is important to their communities while $8.31 \%$ do not. Furthermore, $79.07 \%$ and $64.00 \%$ of respondents agree that the enhancement of vegetation richness and the dispersion of green space is significant. Of the respondents, $75.38 \%$ recognize that developing or restoring wetlands 
is essential for their neighborhoods while $10.15 \%$ disagree. In terms of improving water quality and restoring wetland, $4.00 \%$ and $8.31 \%$ disagree that it is necessary.

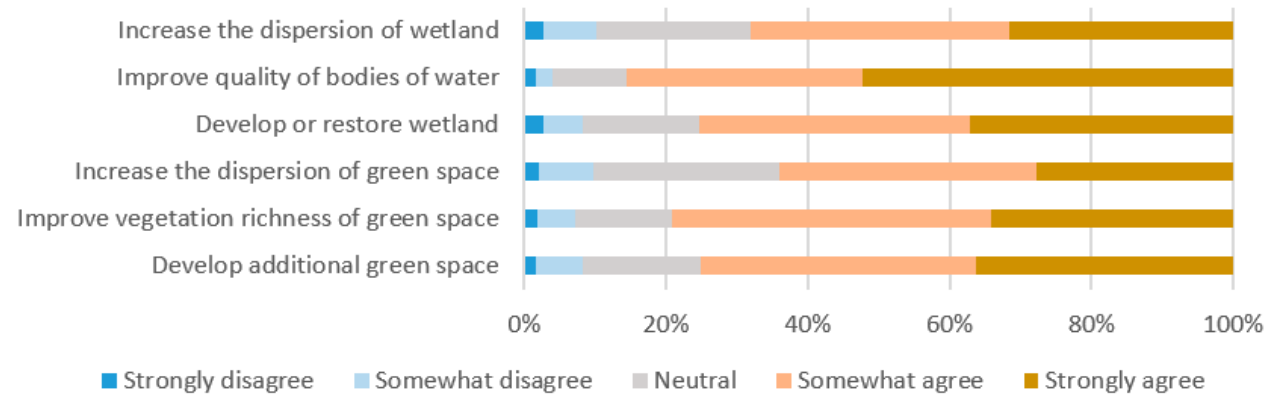

Figure 11. Perception of green open space improvement.

Those who disagree mainly report an improvement or no change in the quality of water bodies. The results show that a person's experience with natural space change affects their view of the necessity of improvement. An increase in natural space may reduce the perceived necessity of the improvement, while a decrease may play an opposite role.

Comparing mean scores (Figure 12), gender and age affect perceptions of the need to improve the quality of bodies of water, for which males (4.22) agree less than females (4.41), and elders (4.05) are less likely to agree than middle-aged (4.41) and young (4.41) residents. Hukou affects residents' perception of improving vegetation richness and developing or restoring wetland; urban Hukou people (2.50) are in greater disagreement that improving vegetation richness is needed than rural Hukou residents (2.66) but more agree that developing or restoring wetland is important (urban Hukou 4.08 and rural Hukou 3.82).

In terms of preferences, respondents' visiting frequency affects their evaluation of the necessity to increase the dispersion of green space. Those who visit often disagree more than those who visit less. In-person services enjoyed by visitors are associated with the need for improvements to green open spaces (Figure 12). Enjoying green open space to walk, enjoy nature, and exercise is significantly associated with perceptions of improving vegetation richness, increasing the dispersion of green space, developing wetland, and improving the quality of bodies of water.

Regarding reported experience of green space changes, respondents that experienced a great decrease in green space present the strongest agreement with the necessity to develop additional green space in their neighborhoods. A similar perception also represents the importance of developing or restoring wetland.

\subsubsection{Perceptions of Needed Facility Improvement}

In terms of improving auxiliary facilities in green space, the survey focuses on the importance of enhancing trails, exercise facilities, bicycle lanes, and children's playgrounds. Of the respondents, $76.31 \%$ agree and $4.62 \%$ disagree that improving trails is significant (Figure 13). Regarding the increase in exercise facilities, $72.92 \%$ of respondents agree that it is important in their neighborhoods and $8.62 \%$ disagree. Among those who disagree, $92.86 \%$ use green space for a variety of reasons except exercise. Of the respondents, $67.38 \%$ agree and $8.92 \%$ disagree that improving bicycle trails is obligatory. Of those who disagree, $89.65 \%$ visit green open space by foot to walk, with no motive of bicycling; only $10.35 \%$ visit for bicycling but none notice a lack of trails. Furthermore, $62.46 \%$ agree and $9.23 \%$ disagree that improving children's playgrounds is important. However, none of the interviewees who visit green open space for children's play disagree. In summary, the necessity for auxiliary facilities improvement in green open space relies on the residents' intention for visiting, indicating a practically oriented demand for improvements. 


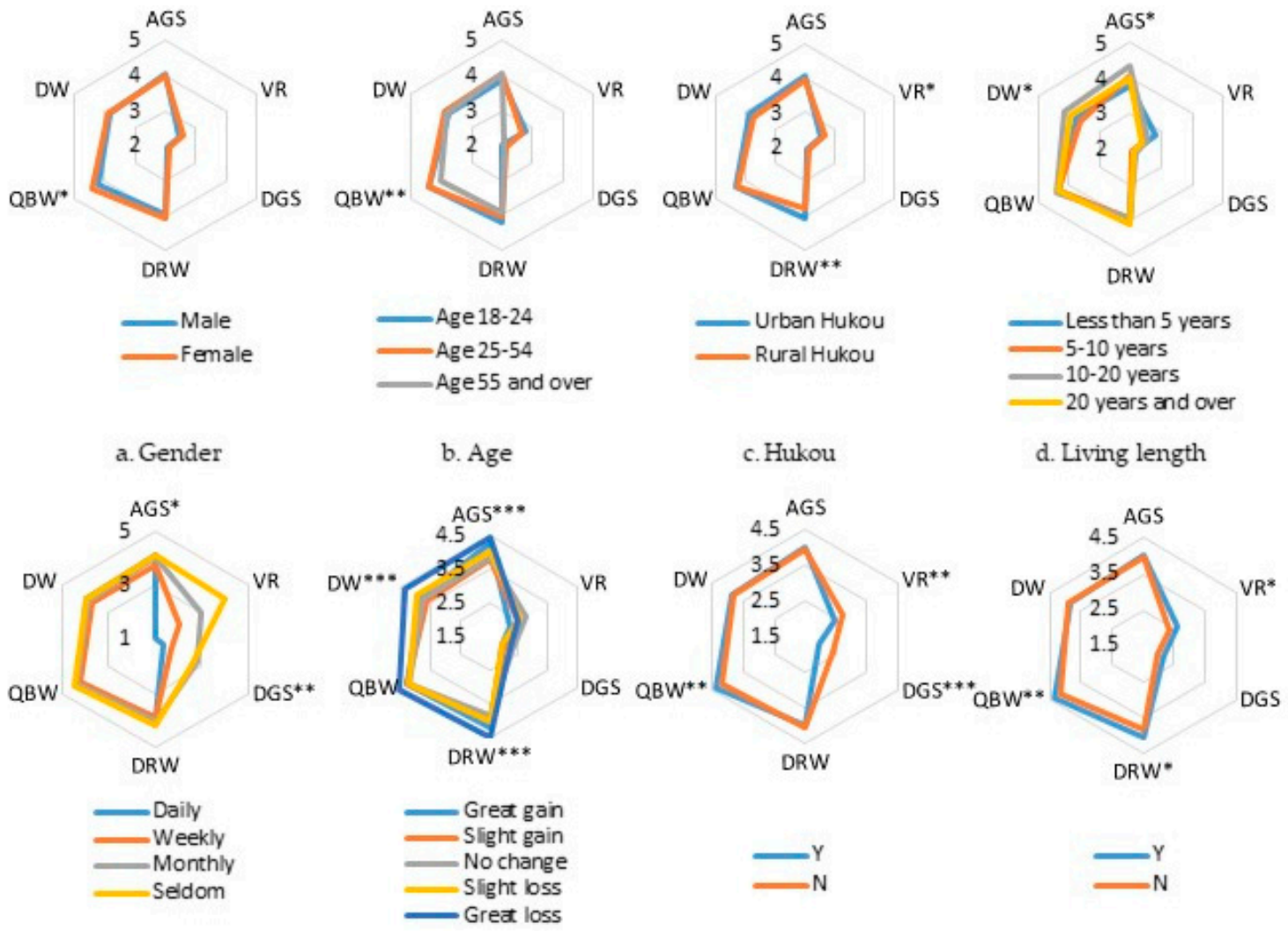

e. Visit frequency f. Loss of gain of green space $\quad \mathrm{g}$. Visit for walking $\quad \mathrm{h}$. Visit for enjoying nature

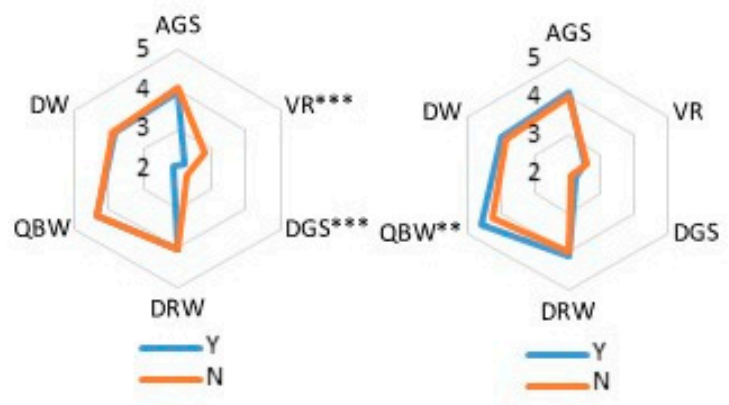

i. Visit for exercise

j. Visit for socializing
AGS: Develop ạdditional green space

VR: Improvevegetation nichness

DGS: Increase dispersion of green space

DRW: Develop or restone wetland

QBW: Improve quality of bodies of water

DW: Increasedispersion of wetland

P value: ${ }^{* *},{ }^{* *},{ }^{*}$ indicates the significance of Kruskal Wallis' test at the level of $0.01,0.05$, and 0.10 , respectively.

Figure 12. Social difference of natural space improvement perceptions (based on mean score).

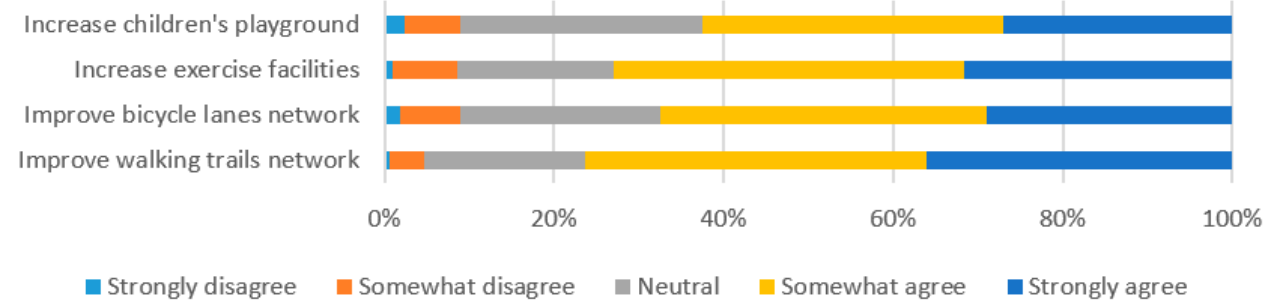

Figure 13. Perception of facility improvement in green open space.

Gender, age, and education do not significantly impact residents' perceptions of the needed improvements to facilities in urban green spaces (Figure 14). Hukou is of greater influence, with rural populations more likely to be neutral or disagree that facilities should be improved. Different occupations face significant discrimination when evaluating the necessity of improving facilities. Students tend to be the most neutral and likely to disagree 
on increasing walking trails (3.75) and children's playgrounds (3.28). Intellectuals agree most with increasing walking trails (4.35) and children's playgrounds (4.04), followed by businesspeople (4.15). The length of residency also influences perceptions of facility improvement; those who have lived in Wuhan longer are more in favor of facility improvements than those with shorter residency. In terms of the reported experience of green space changes, those who have witnessed a great decrease in green space agree much more strongly with the necessity of facility improvement than the other respondents.

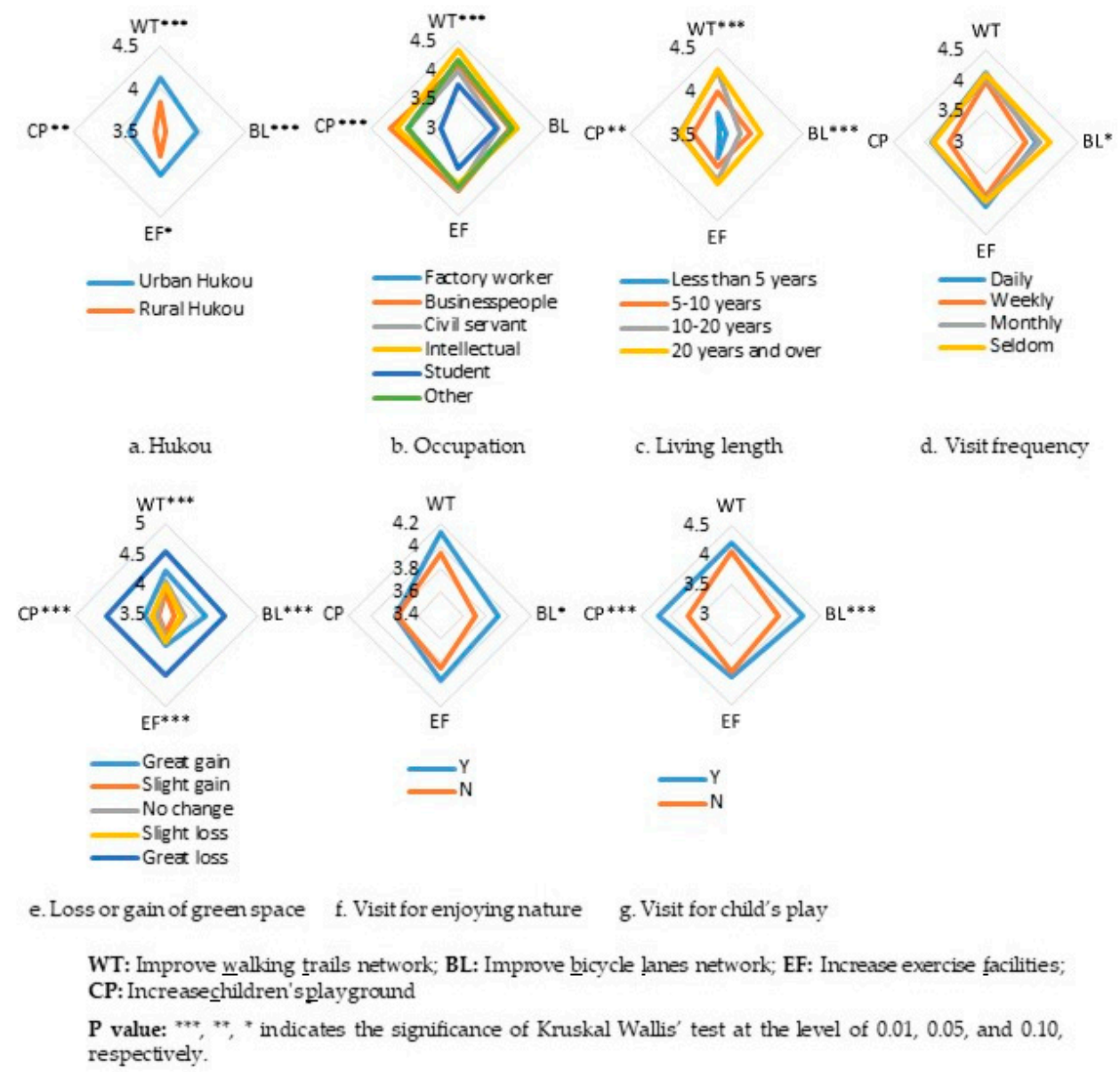

Figure 14. Social difference in perception of facility improvement (based on mean scores).

\subsection{Interview Results}

We interviewed eighteen participants. The interviewees included seven (almost 40\%) males and eleven (slightly over 60\%) females. Their occupations vary, with one factory worker, four businesspeople, three civil servants, five researchers, and five students. They live in various districts with different lengths of residency, ranging from 3 years to more than 20 years. Eight of the interviewees visit green open space daily, four visit weekly, and the other six visit monthly or less. The objectives behind the interviews were to gain more insight into what affects respondents' visiting frequencies to green open space, how they perceive benefits, impacts, and improvements of green open space, and their willingness to participate in green open space planning and management. The interview results are briefly presented in Table 3. 
Table 3. Summary of interview.

\begin{tabular}{ll}
\hline Question Theme & \multicolumn{1}{c}{ Summary } \\
\hline & Twelve interviewees claim that the \\
proximity of green open space in their \\
neighborhoods is the most important \\
factor affecting their visit frequency. \\
Proximity of green open space & $\begin{array}{l}\text { Sixterviewees do not believe the } \\
\text { proximity is a determinant for their visit } \\
\text { frequency. Four of them said they do not } \\
\text { have much flexible time due to busy } \\
\text { schedules. The other two rarely visit } \\
\text { since it is not a habit. }\end{array}$ \\
\hline
\end{tabular}

Fourteen participants approve of improving natural space as well as auxiliary facilities in their neighborhood. Four participants did not express their view on the necessity. Two of them enjoy high-quality green open space close to their residential community and the other two have witnessed a great increase in green space in their neighborhoods.
"In my neighborhood, the green open space is close by and very convenient to be accessed. I go there every morning and evening for dancing. It is very important for my health," expressed a 50-year-old female researcher. "I am very busy with my business and hardly have leisure time to visit the green open space, even though it is not far away. But I really enjoy the green environment as I walk by," said a 32-year-old businessman.

"I would prefer to increase the green open space and fitness facilities in my neighborhood. I visit the space 2-3 times per week to walk and enjoy nature, often I use the facilities to exercise. This mitigates my back aches and promotes my health," a 38-year-old civil servant said. "In my neighborhood, there is ample green open space, with exercise facilities such as basketball court, tennis court, etc. I enjoy the space and facilities very often. So I don't think it is necessary to make improvement," a 32-year-old researcher.

"Green open space is very important for high-quality life. I reside close to JiangTan park and visit there almost every day, for enjoying nature and relaxation. I notice that it is really good for my health," said a 50-year-old civil servant.

"Green open space is of great significance to a high-quality environment and is beneficial to the daily life of residents. But for me, green space does not mean a place to relax every day, because I am too busy at work and rarely go outdoors in my free time," a 35-year-old businessman.

"The green open space I usually visit is only a 5-min walk away from my apartment. I am used to going there every day. In the morning and evening, many residents living nearby dance here, which is very lively. But sometimes it is too noisy," an interviewee who lives in an apartment near the Street Park.

"The open green space in the community where I live is a bit remote and lacks lighting, so for safety, I usually go there during the day," a 22-year-old student said. 
Table 3. Cont.

\begin{tabular}{|c|c|c|}
\hline Question Theme & Summary & Example Quote(s) \\
\hline Willingness to participate & $\begin{array}{l}\text { Nine participants show willingness to be } \\
\text { engaged in green open space } \\
\text { configuration and maintenance. They are } \\
\text { more likely to be middle aged. } \\
\text { Five participants doubt the effectiveness } \\
\text { of the public's contribution since they feel } \\
\text { decision makers will not take residents' } \\
\text { opinions seriously. } \\
\text { The other four participants did not give } \\
\text { clear opinions about their participation } \\
\text { willingness. }\end{array}$ & $\begin{array}{l}\text { "I am very enthusiastic to be involved in the } \\
\text { configuration and maintenance of green open } \\
\text { spaces in the community. For example, I often } \\
\text { collect residents' needs and provide } \\
\text { suggestions to the Property Management } \\
\text { Board. If more residents participate, the } \\
\text { community will have a better environment. I } \\
\text { believe many hands make light work," a } \\
45 \text {-year-old female researcher. She is a } \\
\text { member of the owners' committee in her } \\
\text { community. } \\
\text { "Volunteers participating in the maintenance } \\
\text { of community green space can promote the } \\
\text { beautification of the community. I often } \\
\text { engage in this type of voluntary work. I am } \\
\text { also willing to provide feedback for the } \\
\text { configuration and enhancement of } \\
\text { landscaping in the community, but there are } \\
\text { few such channels. I don't think these } \\
\text { proposals would be taken seriously by } \\
\text { decision-makers. Economic interests are often } \\
\text { sought first by developers," said a } \\
24 \text {-year-old student. }\end{array}$ \\
\hline
\end{tabular}

\section{Discussions}

\subsection{Respondents' Preferences of Green Open Space and Link with Perceptions}

The survey results show that respondents most enjoy visiting green open space to be around nature, go walking, and exercise. This is coincident with the findings for Guangzhou in China [35] and for Gyeongsan City in the Republic of Korea [41]. However, perceived benefits of green open space differ between this study and Jim and Shan's [15] results. For example, while popular in Jim and Shan's study, child's play is not a most common benefit enjoyed by residents in this research. This is due to differences in sampling as the sampling in this study focuses on those over 18 years old and a small proportion have minors, whereas the literature includes samples aged 14-18. Socializing is recognized as a minor function that fewer people enjoy. The results support findings in Guangzhou [15] and in Malaysia [50] that residents might not use urban green open space as an important place for social interaction, although it offers the environment for it.

Intentions to visit in person are connected to respondents' perceptions of improvements of natural space, distribution, and corresponding facility improvements. Those who visit to go walking, enjoy nature or exercise prefer the improvement of natural elements such as increasing greenness and water areas in green open spaces, while those who go for child's play are interested in the improvement of auxiliary facilities such as children's playgrounds. An understanding of needed facility improvements demonstrates a practical orientation demand which has also been found in Chinese cities such as Guangzhou [15] and Zhengzhou [51]. The improvements then attract more visits which further enhance people's cognition of the corresponding services.

Similar findings in the literature focusing on other regions, such as cities in the Netherlands, [38] show that youth prefer to use green open space for socializing more than elders do. Meanwhile, businesspeople and students tend to socialize more than other occupational groups. Elders mostly prefer going to green open space for exercise, indicating a health concern associated with age, which is also reflected in the literature about elder visitors' behaviors or concerns [39,52]. 
Rural Hukou implicates more natural and social interaction in residents' growing experience. It also results in higher preferences for walking, enjoying nature, and socializing. This finding implies that growing up in a more natural environment has an inherent effect on adults' preference for green open space. It is in line with the claim that childhood experience influences adults' green place visiting behavior, which has been studied in cities of Britain [53].

Intellectuals, who mainly have highly educated backgrounds, prefer child's play in green open space the most, compared with other occupational respondents. This is mostly caused by the greater proportion of intellectuals with children in the survey. It further implies that the amount of time a child is exposed to nature can have a long-term impact on their preferences and perceptions.

The findings are relevant to urban planning with its practical yet socially dynamic demands of green open space. Thereby, it suggests that green open space configuration planning should be organized with particular attention to the social structure of neighborhoods being served close by. For example, in neighborhoods with more youth, bicycle trails and more social interaction facilities should be considered. In neighborhoods with more minors, children's playgrounds should be addressed, and parking lots might be a potential demand. In neighborhoods with more elders, daily exercise facilities should be stressed.

Social-natural interactions have been changing along with urban evolution. Respondents' preferences relate to their childhood experiences with the social and natural environment and are affected by the actual environment they are in currently. In terms of social interaction, those who live in a traditional neighborhood or a workplace neighborhood have more familiarities and prefer more socializing rather than those in a modern neighborhood. However, increasing developments of new technology and high-rise vertical residential structures, to a great extent, decreased social contact. Therefore, designing people-friendly green open space is helpful for the promotion of social interaction.

In current neighborhoods, the feasibility to add more green space or wetland is largely constrained by reality, even though respondents express strong demands. In the regenerated neighborhoods, a soft landscape has been improved according to the planning criteria about property ratios and green space percentages. In upcoming neighborhoods, decision makers should consider the census information regarding population structure, which is the subject of green open space usage. Corresponding designs should be introduced according to the population structure and the surveyed demands for green open space.

\subsection{Social Factors' Influences on Residents' Perceptions}

The ecological services closely related to daily life and enjoyment, such as fresh air, urban heat island relief, and urban noise mitigation, attract more agreement than other services that relate indirectly. The results in Guangzhou, China express similar beliefs [41]. Through these services, green open space benefits respondents' daily life and health [54]. Demands for improvement to green open space from the perspective of area, richness, configuration, and auxiliary facilities are rooted in residents' appreciation for daily relaxation and health benefits. An improved green open system then provides better benefits for respondents' daily leisure as well as their health. However, even though participants strongly agree that green open space is beneficial for daily relaxation and health, it does not reflect upon their use of these spaces when looking at frequency and intention of visiting. It reveals that green open space benefits people without relying on an in-person visit.

Participants mostly agree that green open spaces are consistent with their health and needs for daily leisure or relaxation. Differences between those with urban versus rural Hukou, as well as in terms of length of residency, show that nature interaction background and knowledge of nature development affect perception of daily use and health-related services provided by green open spaces. This supports studies of experiences in nature [55]. These differences are also found when residents evaluate the benefits of urban heat island relief by green open space. In Wuhan, the "Furnace City", which has extremely high 
temperatures in specific seasons, the heat island relief function is recognized as being very important. The perception of this service is also demonstrated in another "Furnace City", Nanjing [56].

Compared with other occupational groups, factory workers agree the most that green open spaces reduce noise. In neighborhoods relying on the traditional secondary industry, improvements to green open space have been outstanding since the 2000s [57]. The transition influences workers' feelings about the improvement of the environment, especially regarding noise mitigation. It supports studies in cities that have similar traditional industrial transformation and upgrading. Noise reduction services are also strongly agreed upon by those living in Wuhan longer and those who have experienced great changes in natural space.

A relatively higher proportion of respondents disagree that green open space is conducive to community safety. Disagreements, according to the interviews, are due to some negative impacts by the visitors or by the space itself, such as too many visitors, noise caused by visiting, environmental degradation, etc. Findings on Chinese cities mainly stress the positive contribution of green open space to a high-quality residential environment, which support literature on south-east Asian cities [58] and North American cities [59]. In China's high-density cities, the scarcity of green open spaces means that these spaces have more positive effects on the living environment than negative impacts. Further, more conveniently accessible green open space (based on increased dispersion) and rich greenness may increase real estate value, though a higher proportion of respondents disagree with this claim than with other social services.

\subsection{Influence of Experience on Cognition}

Hukou, residential length, and reported green space change are three factors referring to respondents' experiences. Rural Hukou implies that respondents were raised in an environment with more interaction with the natural environment and people. Regarding length of residency, those who have lived in Wuhan longer may have more experience and knowledge about urban landscape evolution as well as its ecological services. Another experience-related factor is reported green space changes in the neighborhoods in which respondents reside. Respondents who were raised in an urban environment tend to agree more with the claim that green open space is important for both natural and social services than those in a rural environment and those who have lived in Wuhan longer agree more with the improvement than those with a shorter length of residency.

Experience of development in green space alters perspectives toward the areas. Taking it as an independent variable is effective to get clear results about its influences on one's perception. Nonetheless, since it is perceived information, it is better to interpret the findings combined with those based on objective information. Respondents share a variety of experiences with natural space changes. How someone uses and sees natural space changes directly affect how important they think the space and resources are, as well as how involved they are in contributing to a healthy urban ecological system. Respondents who experienced a great decrease in green space approve more of green open spaces' significance for ecological services, indicating a bigger magnitude of environmental degradation has a greater impact on the benefits perceived by residents. The increasing awareness of natural environment promotes more demands for more widely dispersion of green open space in areas near respondents' places of residence.

When determining the differences between services, participants express greater concern about air quality, noise, and flood-related services than hydrological regulation and habitat conservation. One reason is that the former aspects are more directly linked to life quality that residents can directly feel than the latter. Another reason is that most who strongly approve of those benefits have had an experience with environmental degradation at the former stage of urban construction and upgrading at the latter stage. The personal experience of environmental quality dynamics strengthens their agreement with the benefits green open space provides. 


\subsection{Implication on Public Participation}

Respondents' perceptions toward the improvement of green open spaces show that the public can provide suggestions on upgrading those spaces based on their visits, experience, and overall expectations. Public involvement in community green open space configuration and management is common in cities of high-income countries [60]. This approach is gradually being implemented in Chinese cities. Starting in the mid-2000s, large cities in China began an inclusive system for city planning [61], in which capacity ratio and green open space configuration for residential layout are open to the public. This is a remarkable step towards public involvement in China's city planning. In addition, at the community level, residents are encouraged to participate in the maintenance and management of green open spaces, by contributing to popular science activities, cleaning parks, adopting trees, and providing suggestions.

The participants' suggestions to improve green open space demonstrate the potential benefit that could be obtained through their engagement in micro-spatial natural open space management. Their concerns link with the intentions of natural space visits. However, it does not mean they necessarily have a strong willingness to participate in the decisionmaking process, even though valuable information can be obtained from the public. As shown in the interview results, residents' views on the effects of this process are mixed. These differences are caused by varying occupations and experiences with the policymaking institution as well as how public participation plays a role in the system. To promote public participation in a more practical and inclusive process, pre-training needs to be stressed to update information about public processes as well as other stakeholders' concerns.

\section{Conclusions}

This study provides an in-depth analysis of both the social and iconological dimensions of green open space. It refers to the public's involvement with natural landscape evolution and how the landscape can shape people's preferences and perceptions, with a comprehensive understanding of ecological services of, and importance to improve, green open space. It considers Wuhan's characteristics of bodies of water, which are typical in central or southern Chinese cities.

It can be concluded that green open spaces play an important role in maintaining a good quality of residents' daily life and outdoor activities, based on the respondents' preferences and perceptions in the study area of the Wuhan UDZ. Green open space provides many services, such as being an outdoor venue for walking, enjoying nature, exercising, child's play, social interactions, and so on. Preferences vary among different social groups, which results in different perceptions of ecological services provided by green open spaces and the necessary improvements to such spaces. Green open spaces offer an environment for society to connect with nature. How respondents use those spaces for socializing attracts relatively less concern compared with other services. Social interactions are important for healthy social ecology. In order to encourage residents to enjoy more of the services urban green open spaces provide, it is better to learn planning and design from other large cities. The natural ecological services enjoyed by respondents reflect their concern about relative environmental disadvantages. This is related not only to their usage, but also to their experiences with the evolution of the natural subsystem. Even though the ecological services are enjoyed and recognized by respondents, this does not necessarily indicate voluntary participation in green open space management. Cities with relatively mature institutes of volunteer enrollment and training may offer their advice and experiences with public engagement to Chinese cities, even though there may be differences in culture and institutes.

The research provides findings that support the literature from social perspectives. In terms of theory, it also highlights the contributions of environmental experience-based knowledge to perception and the impact of residents' use of green open space on their perception. It enriches ideas regarding social-natural subsystem interactions within an 
urban area. Moreover, a semi-quantitative (questionnaire survey) and qualitative (interview) analysis are combined to eliminate the drawbacks of either approach. Therefore, this research should be considered an upgrade of other approaches in the literature.

Author Contributions: Conceptualization, L.Z. and H.C.; methodology, L.Z. and H.C.; data analysis, L.Z.; writing-original draft preparation, L.Z.; writing-review and editing, L.Z., H.C. and R.H.; supervision, H.C.; project administration, H.C. and L.Z.; funding acquisition, H.C. All authors have read and agreed to the published version of the manuscript.

Funding: This research was funded by the International Council of Canadian, Chinese, African Sustainable Urban Development (ICCCASU), a think tank jointly established by UN-Habitat and the University of Ottawa.

Institutional Review Board Statement: The study was conducted according to the guidelines of the Declaration of Helsinki, and approved by the Ethics Committee of University of Ottawa (S-02-19-2749 on 23 April 2019).

Informed Consent Statement: Informed consent was obtained from all subjects involved in the study.

Data Availability Statement: The data presented in this study are available on request from the corresponding author. The data are not publicly available due to ethical restrictions.

Conflicts of Interest: The authors declare no conflict of interest. The funders had no role in the design of the study; in the collection, analyses, or interpretation of data; in the writing of the manuscript, or in the decision to publish the results.

\section{References}

1. Liu, Z.; Cao, H. Spatio-temporal urban social landscape transformation in pre-new-urbanization era of Tianjin, China. Environ. Plan. B Urban Anal. City Sci. 2017, 44, 398-424. [CrossRef]

2. Belčáková, I.; Świąder, M.; Bartyna-Zielińska, M. The green infrastructure in cities as a tool for climate change adaptation and mitigation: Slovakian and Polish experiences. Atmosphere 2019, 10, 552. [CrossRef]

3. Wang, H.; Dai, X.; Wu, J.; Wu, X.; Nie, X. Influence of urban green open space on residents' physical activity in China. BMC Public Health 2019, 19, 1093. [CrossRef] [PubMed]

4. Han, R.; Cao, H.; Liu, Z. Studying the urban hierarchical pattern and spatial structure of China using a synthesized gravity model. Sci. China Earth Sci. 2018, 61, 1818-1831. [CrossRef]

5. Wolch, J.R.; Byrne, J.; Newell, J.P. Urban green space, public health, and environmental justice: The challenge of making cities 'just green enough'. Landsc. Urban Plan. 2014, 125, 234-244. [CrossRef]

6. Włodarczyk-Marciniak, R.; Sikorska, D.; Krauze, K. Residents' awareness of the role of informal green spaces in a post-industrial city, with a focus on regulating services and urban adaptation potential. Sustain. Cities Soc. 2020, 59, 102236. [CrossRef]

7. Zhou, W.; Zhang, S.; Yu, W.; Wang, J.; Wang, W. Effects of urban expansion on forest loss and fragmentation in six megaregions, China. Remote Sens. 2017, 9, 991. [CrossRef]

8. Islam, M.S.; Rana, M.M.P.; Ahmed, R. Environmental perception during rapid population growth and urbanization: A case study of Dhaka city. Environ. Dev. Sustain. 2014, 16, 443-453. [CrossRef]

9. Thongyou, M.; Chamaratana, T.; Phongsiri, M.; Sosamphanh, B. Perceptions on urbanization impact on the hinterlands: A study of Khon Kaen City, Thailand. Asian Soc. Sci. 2014, 10, 33-41. [CrossRef]

10. Shirazi, S.A.; Kazmi, J.H. Analysis of socio-environmental impacts of the loss of urban trees and vegetation in Lahore, Pakistan: A review of public perception. Ecol. Process. 2016, 5, 5. [CrossRef]

11. Zhang, H.; Chen, B.; Sun, Z.; Bao, Z. Landscape perception and recreation needs in urban green space in Fuyang, Hangzhou, China. Urban For. Urban Green. 2013, 12, 44-52. [CrossRef]

12. Gaudreau, M.; Cao, H. Political constraints on adaptive governance: Environmental NGO networks in Nanjing, China. J. Environ. Dev. 2015, 24, 418-444. [CrossRef]

13. Kothencz, G.; Kolcsár, R.; Cabrera-Barona, P.; Szilassi, P. Urban green space perception and its contribution to well-being. Int. J. Environ. Res. Public Health 2017, 14, 766. [CrossRef] [PubMed]

14. Lo, A.Y.; Jim, C.Y. Citizen attitude and expectation towards greenspace provision in compact urban milieu. Land Use Policy 2012, 29, 577-586. [CrossRef]

15. Jim, C.Y.; Shan, X. Socioeconomic effect on perception of urban green spaces in Guangzhou, China. Cities 2013, 31, 123-131. [CrossRef]

16. Wendel, H.E.W.; Zarger, R.K.; Mihelcic, J.R. Accessibility and usability: Green space preferences, perceptions, and barriers in a rapidly urbanizing city in Latin America. Landsc. Urban Plan. 2012, 107, 272-282. [CrossRef] 
17. Zhang, J.; Yu, Z.; Cheng, Y.; Chen, C.; Wan, Y.; Zhao, B.; Vejre, H. Evaluating the disparities in urban green space provision in communities with diverse built environments: The case of a rapidly urbanizing Chinese city. Build. Environ. 2020, 183, 107170. [CrossRef]

18. Wu, J.; He, Q.; Chen, Y.; Lin, J.; Wang, S. Dismantling the fence for social justice? Evidence based on the inequity of urban green space accessibility in the central urban area of Beijing. Environ. Plan. B Urban Anal. City Sci. 2020, 47, 626-644. [CrossRef]

19. He, S.; Wu, Y.; Wang, L. Characterizing horizontal and vertical perspectives of spatial equity for various urban green spaces: A case study of Wuhan, China. Front. Public Health 2020, 8, 10. [CrossRef]

20. Astell-Burt, T.; Feng, X.; Mavoa, S.; Badland, H.; Giles-Corti, B. Do low-income neighbourhoods have the least green space? A cross-sectional study of Australia's most populous cities. BMC Public Health 2014, 14, 292. [CrossRef]

21. Lin, B.; Meyers, J.; Barnett, G. Understanding the potential loss and inequities of green space distribution with urban densification. Urban For. Urban Green. 2015, 14, 952-958. [CrossRef]

22. Lovell, S.T.; Taylor, J.R. Supplying urban ecosystem services through multifunctional green infrastructure in the United States. Landsc. Ecol. 2013, 28, 1447-1463. [CrossRef]

23. Irvine, K.N.; Warber, S.L.; Devine-Wright, P.; Gaston, K.J. Understanding urban green space as a health resource: A qualitative comparison of visit motivation and derived effects among park users in Sheffield, UK. Int. J. Environ. Res. Public Health 2013, 10, 417-442. [CrossRef] [PubMed]

24. Jim, C.Y.; Chen, W.Y. Perception and attitude of residents toward urban green spaces in Guangzhou (China). Environ. Manag. 2006, 38, 338-349. [CrossRef] [PubMed]

25. Zuniga-Teran, A.A.; Stoker, P.; Gimblett, R.H.; Orr, B.J.; Marsh, S.E.; Guertin, D.P.; Chalfoun, N.V. Exploring the influence of neighborhood walkability on the frequency of use of greenspace. Landsc. Urban Plan. 2019, 190, 103609. [CrossRef]

26. Farahani, L.M.; Maller, C.J. Perceptions and preferences of Urban greenspaces: A literature review and framework for policy and practice. Landsc. Online 2018, 61, 1-22. [CrossRef]

27. Rishbeth, C. Ethnic Minority Groups and the Design of Public Open Space: An inclusive landscape? Landsc. Res. 2010, 26, 351-366. [CrossRef]

28. Tian, Y.; Wu, H.; Zhang, G.; Wang, L.; Zheng, D.; Li, S. Perceptions of ecosystem services, disservices and willingness-to-pay for urban green space conservation. J. Environ. Manag. 2020, 260, 110140. [CrossRef]

29. Cleary, A.; Fielding, K.S.; Murray, Z.; Roiko, A. Predictors of nature connection among urban residents: Assessing the role of childhood and adult nature experiences. Environ. Behav. 2020, 52, 579-610. [CrossRef]

30. Yuen, B.; Hien, W.N. Resident perceptions and expectations of rooftop gardens in Singapore. Landsc. Urban Plan. 2005, 73, 263-276. [CrossRef]

31. Gunnarsson, B.; Knez, I.; Hedblom, M.; Sang, A.O. Effects of biodiversity and environment-related attitude on perception of urban green space. Urban Ecosyst. 2017, 20, 37-49. [CrossRef]

32. Xue, F.; Gou, Z.; Lau, S.S.Y. Green open space in high-dense Asian cities: Site configurations, microclimates and users' perceptions. Sustain. Cities Soc. 2017, 34, 114-125. [CrossRef]

33. Chen, Y.; Ke, X.; Min, M.; Cheng, P. Disparity in perceptions of social values for ecosystem services of urban green space: A case study in the East Lake Scenic Area, Wuhan. Front. Public Health 2020, 8, 370. [CrossRef] [PubMed]

34. Ayala-Azcárraga, C.; Diaz, D.; Zambrano, L. Characteristics of urban parks and their relation to user well-being. Landsc. Urban Plan. 2019, 189, 27-35. [CrossRef]

35. Sang, Å.O.; Knez, I.; Gunnarsson, B.; Hedblom, M. The effects of naturalness, gender, and age on how urban green space is perceived and used. Urban For. Urban Green. 2016, 18, 268-276. [CrossRef]

36. Hazer, M.; Formica, M.K.; Dieterlen, S.; Morley, C.P. The relationship between self-reported exposure to greenspace and human stress in Baltimore, MD. Landsc. Urban Plan. 2018, 169, 47-56. [CrossRef]

37. Twohig-Bennett, C.; Jones, A. The health benefits of the great outdoors: A systematic review and meta-analysis of greenspace exposure and health outcomes. Environ. Res. 2018, 166, 628-637. [CrossRef]

38. Mattijssen, T.J.M.; van der Jagt, A.P.; Buijs, A.E.; Elands, B.H.M.; Erlwein, S.; Lafortezza, R. The long-term prospects of citizens managing urban green space: From place making to place-keeping? Urban For. Urban Green. 2017, 26, 78-84. [CrossRef]

39. Santo-Tomás Muro, R.; Sáenz de Tejada Granados, C.; Rodríguez Romero, E.J. Green infrastructures in the peri-urban landscape: Exploring local perception of well-being through 'go-alongs' and 'semi-structured interviews'. Sustainability 2020, $12,6836$. [CrossRef]

40. Paul, S.; Nagendra, H. Factors influencing perceptions and use of urban nature: Surveys of park visitors in Delhi. Land 2017, 6, 27. [CrossRef]

41. Lee, Y.C.; Kim, K.H. Attitudes of citizens towards urban parks and green spaces for urban sustainability: The case of Gyeongsan City, Republic of Korea. Sustainability 2015, 7, 8240-8254. [CrossRef]

42. Riechers, M.; Barkmann, J.; Tscharntke, T. Perceptions of cultural ecosystem services from urban green. Ecosyst. Serv. 2016, 17, 33-39. [CrossRef]

43. Rupprecht, C.D. Informal urban green space: Residents' perception, use, and management preferences across four major Japanese shrinking cities. Land 2017, 6, 59. [CrossRef]

44. Kruskal-Wallis H Test Using SPSS Statistics. 2020. Available online: https://statistics.laerd.com/spss-tutorials/kruskal-wallis-htest-using-spss-statistics.php (accessed on 25 December 2020). 
45. Jamieson, S. Likert scales: How to (ab) use them? Med. Educ. 2004, 38, 1217-1218. [CrossRef]

46. Allen, I.E.; Seaman, C.A. Likert scales and data analyses. Qual. Prog. 2007, 40, 64-65.

47. Norman, G. Likert scales, levels of measurement and the "laws" of statistics. Adv. Health Sci. Educ. 2010, 15, 625-632. [CrossRef]

48. Uher, J. Quantitative data from rating scales: An epistemological and methodological enquiry. Front. Psychol. $2018,9,2599$. [CrossRef]

49. Sullivan, G.M.; Artino, A.R., Jr. Analyzing and interpreting data from Likert-type scales. J. Grad. Med. Educ. 2013, 5, 541-542. [CrossRef]

50. Rasidi, M.H.; Jamirsah, N.; Said, I. Urban green space design affects urban residents' social interaction. Procedia Soc. Behav. Sci. 2012, 68, 464-480. [CrossRef]

51. Mao, Q.; Wang, L.; Guo, Q.; Li, Y.; Liu, M.; Xu, G. Evaluating cultural ecosystem services of urban residential green spaces from the perspective of residents' satisfaction with green space. Front. Public Health 2020, 8, 226. [CrossRef]

52. Wen, C.; Albert, C.; Von Haaren, C. The elderly in green spaces: Exploring requirements and preferences concerning nature-based recreation. Sustain. Cities Soc. 2018, 38, 582-593. [CrossRef]

53. Thompson, C.W.; Aspinall, P.; Montarzino, A. The childhood factor: Adult visits to green places and the significance of childhood experience. Environ. Behav. 2008, 40, 111-143. [CrossRef]

54. Zupancic, T.; Westmacott, C.; Bulthuis, M. The Impact of Green Space on Heat and Air Pollution in Urban Communities: A Meta-Narrative Systematic Review; David Suzuki Foundation: Vancouver, BC, Canada, 2015; p. 67.

55. Rosa, C.D.; Collado, S. Experiences in nature and environmental attitudes and behaviors: Setting the ground for future research. Front. Psychol. 2019, 10, 763. [CrossRef] [PubMed]

56. Rui, L.; Buccolieri, R.; Gao, Z.; Ding, W.; Shen, J. The impact of green space layouts on microclimate and air quality in residential districts of Nanjing, China. Forests 2018, 9, 224. [CrossRef]

57. Lai, Y.; Chen, K.; Zhang, J.; Liu, F. Transformation of industrial land in urban renewal in Shenzhen, China. Land 2020, 9, 371. [CrossRef]

58. Wolfe, M.K.; Mennis, J. Does vegetation encourage or suppress urban crime? Evidence from Philadelphia, PA. Landsc. Urban Plan. 2012, 108, 112-122. [CrossRef]

59. Kondo, M.C.; Han, S.; Donovan, G.H.; MacDonald, J.M. The association between urban trees and crime: Evidence from the spread of the emerald ash borer in Cincinnati. Landsc. Urban Plan. 2017, 157, 193-199. [CrossRef]

60. Buijs, A.; Mattijssen, T.; Van der Jagt, A.; Ambrose-Oji, B.; Andersson, E.; Elands, B.; Steen Møller, M. Active citizenship for urban green infrastructure: Fostering the diversity and dynamics of citizen contributions through mosaic governance. Curr. Opin. Environ. Sustain. 2016, 22, 1-6. [CrossRef]

61. Lin, L.X.; Xia, B.; Hu, Y.; Shan, M.; Le, Y.; Chen, A.P.C. Public participation performance in public construction projects of South China: A case study of the Guangzhou Games venue construction. Int. J. Proj. Manag. 2017, 35, 1391-1401. 